\title{
Programa "Tempo de Justiça": análises quali-quantitativas dos acórdãos decorrentes de julgamento de recurso em sentido restrito no Tribunal de Justiça do Estado do Ceará
}

https://doi.org/10.21814/uminho.ed.30.25

Nestor Eduardo Araruna Santiago
Professor Titular da Universidade de Fortaleza (UNIFOR)
Juliana Maria Borges Mamede
Professora da Universidade de Fortaleza (UNIFOR)
Ítalo Farias Braga
Doutorando e Mestre em Direito Constitucional pela
Universidade de Fortaleza (UNIFOR)
Bianca Maria Simão Franco
Mestranda bolsista pela Universidade de Fortaleza (UNIFOR)
Lyara Maria Peres Ximenes
Graduanda em Direito pela Universidade de Fortaleza (UNIFOR)

\section{Introdução}

O Programa Tempo de Justiça, integrante do "Pacto por um Ceará Pacífico", é resultante da parceria entre o Tribunal de Justiça do Estado do Ceará (TJCE), o Ministério Público do Estado do Ceará (MPCE), Defensoria Pública do Estado do Ceará (DPGE), Secretaria de Segurança Pública do Estado do Ceará (SSPCE) e a Vice Governadoria do Estado do Ceará, tendo como objetivo instigar a celeridade nos processos de crimes dolosos contra a vida, submetidos ao rito do Tribunal do Júri ${ }^{1}$.

No intuito de fomentar a celeridade de tramitação desses processos, o Programa Tempo de Justiça tem foco no julgamento dos crimes de homicídio com autoria conhecida, os quais devem ser julgados no prazo máximo de 1 (um) ano. As expectativas residem na diminuição do tempo de tramitação dos processos e na consequente redução do acervo processual nas varas do Tribunal do Júri.

O objetivo principal é verificar se houve aumento na quantidade de interposições de RESE nas Câmaras Criminais do TJ/CE, contra decisões de pronúncia, após a vigência do Programa Tempo de Justiça, averiguando se houve diminuição no tempo de julgamento dos processos de homicídios com autoria conhecida, os quais tramitam nas varas do Tribunal do Júri, no período compreendido entre agosto de 2016 a dezembro de 2018.

1 CEARÁ. Protocolo de Cooperação Interinstitucional. Diário Oficial do Estado do Ceará, Fortaleza, mar. 2017, série 3, ano IX, nº 046, caderno único. 
Além da análise quantitativa do tempo necessário ao julgamento dos RESE, busca-se compreender a aplicabilidade dos princípios do "in dubio pro reo" e do "in dubio pro societate", este último como formulação processual de resposta à dúvida nas decisões de pronúncia, de acordo com a fundamentação dos acórdãos nos casos concretos julgados pelas Câmaras Criminais do TJCE.

Nesse contexto, faz-se necessário analisar a aplicação do princípio "in dubio pro societate" como fundamento jurídico da decisão de pronúncia, em caso de dúvida acerca da existência do crime e/ou sua autoria, em detrimento do "in dubio pro reo", corolário do princípio da presunção do estado de inocência, previsto no art. $5^{\circ}$, LVII, da Constituição Federal ( $\left(\mathrm{F}^{2}\right)$.

A respeito da metodologia do presente artigo, no que diz respeito à abordagem, trata-se de pesquisa quanti-qualitativa. A abordagem quantitativa está pautada no estudo de um critério de representatividade numérica, focado no julgamento dos RESE, considerando uma eventual correlação entre o aumento da quantidade de interposição desse recurso e o maior número de decisões de pronúncia. A abordagem qualitativa está relacionada ao estudo do mérito dos acórdãos proferidos no julgamento dos RESE, ou seja, na fundamentação jurídica utilizada pelos desembargadores das Câmaras Criminais do TJCE para prover ou não o recurso.

A escolha do tema justifica-se pela importância do assunto do ponto de vista social e jurídico, pois é de interesse da sociedade obter uma resposta, em tempo razoável, acerca da condenação ou absolvição do réu. $O$ incremento de decisões de pronúncia no primeiro grau deve gerar um número maior de interposições de Recurso em Sentido Estrito (RESE), o que pode impactar nos prazos de julgamento nas Câmaras Criminais do TJ/CE.

A decisão de pronúncia é de suma importância nesta pesquisa, pois contra essa decisão cabe recurso em sentido estrito (RESE), normalmente interposto pela defesa, de acordo com o art. 581, IV, do Código de Processo Penal (CPP3), hipótese recursal objeto de análise do presente trabalho. 0 juiz pronuncia o réu quando estiver convencido da materialidade do crime e da existência de indícios suficientes de autoria ou de participação, ou seja, a pronúncia é diametralmente oposta à impronúncia.

O Programa Tempo de Justiça busca o respeito ao princípio da razoável duração do processo, previsto no art. $5^{\circ}, \mathrm{LXXVIII,} \mathrm{da} \mathrm{CF}$, que está relacionado à celeridade da tramitação processual. Esse dispositivo foi incluído no ordenamento jurídico brasileiro a partir da Emenda Constitucional $n^{\circ} 45 / 2004$, elaborada pelo poder constituinte derivado reformador, responsável por alterar o texto constitucional originário.

2 BRASIL. Constituição (1988). Constituição da República Federativa do Brasil. Brasília: Senado, 1988. [consultado em 2021-04-14]. Disponível em: http://www.planalto.gov.br/ccivil_03/Constituicao/Constituicao.htm.

3 BRASIL. Presidência da República. Código de Processo Penal. Rio de Janeiro/RJ, 1941. [consultado em 2021-04-14]. Disponível em: http://www.planalto.gov.br/ccivil_03/decreto-lei/Del3689Compilado.htm. 
A Emenda Constitucional retro mencionada firmou o compromisso dos três poderes federativos com o I Pacto Republicano de Estado por um Sistema de Justiça mais acessível, ágil e efetivo, o qual deu suporte para a virtualização dos processos judiciais, mudança imprescindível para se alcançar maior celeridade na realização dos atos processuais. Posteriormente, foi assinado o II Pacto Republicano de Estado, com o intuito de reforçar as metas estabelecidas no primeiro pacto, tais como: o respeito ao Estado Democrático de Direito, a proteção dos direitos humanos e o efetivo acesso ao sistema de justiça brasileiro ${ }^{4}$.

Nesse contexto, pretende-se verificar o tempo considerado como razoável e suficiente, entendido como aquele necessário para a realização do ato, da maneira mais célere, sem que para isso atinja o princípio do devido processo legal. Portanto, é necessário verificar o que seria este transcurso temporal considerado aceitável, ou não muito dilatado, para se adequar aos direitos e garantias fundamentais do réu 5 .

\section{Análise quantitativa do número de recursos em sentido estrito}

Com o fito de verificar se o Programa Tempo de Justiça tem apresentado resultados práticos nos processos de homicídios com autoria conhecida, desenvolveu-se pesquisa quantitativa acerca dos acórdãos proferidos em julgamento dos RESE interpostos nas Câmaras Criminais do TJCE.

\subsection{Metodologia}

Foi adotada a técnica de time series analyses, sequenciando em eixos do plano cartesiano por data e tempo de julgamento, com o intuito de analisar, quantitativamente, os julgados dos RESE interpostos no TJ/CE, a partir de um espaço amostral determinado, seguindo-se o critério Gaussiano.

A pesquisa adveio de coleta amostral dos acórdãos proferidos em julgamento de RESE pelas 3 (três) Câmaras de Direito Criminal do TJCE, no período entre agosto de 2016 a dezembro de 2018. 0 recorte temporal escolhido justifica-se pela criação da Terceira Câmara Criminal no Estado do Ceará, o qual ocorreu no segundo semestre do ano de 2016, levando-se em consideração também o período de disponibilidade de informações. Durante esse tempo, houve 1.551 (mil e quinhentos e cinquenta e um) RESE julgados por todas as Câmaras Criminais.

Com o intuito de viabilizar a realização da pesquisa, ante o elevado número de julgados, decidiu-se selecionar, minimamente, 2 (dois) deles de forma aleatória, por sessão, de cada uma das Câmaras Criminais. Os dados foram dispostos em formato de

4 SANTIAGO, Nestor Eduardo Araruna; DUARTE, Ana Caroline Pinho - Um Conceito de Duração Razoável do Processo Penal. “Novos Estudos Jurídicos", v. 15, n. 2, 2010. [consultado em 2021-04-14]. Disponível em: http://siaiap32.univali.br/seer/index.php/nej/article/view/2596.

5 SCHMITT, C. - Direito à razoável duração do processo no brasil: origens, inobservância e tentativas de concretização. “Revista da Faculdade de Direito da UFG”, v. 34, n. 1, 6 set. 2011. 
cédulas, mediante a criação de tabela pelo programa Excel, sendo coletados a partir de informações públicas contidas nas atas das sessões de julgamento.

Assim, segregou-se um total de 391 (trezentos e noventa e um) acórdãos, aleatoriamente selecionados, com base em, no mínimo, 2 (dois) julgados de sessões por mês. A partir do refinamento destes dados, obteve-se precisão de $95 \%$ na pesquisa, com erro no espaço amostral de $4,23 \%$, de acordo com a fórmula que segue, na qual e $=$ amostra, $z=$ constante padrão, $p=$ proporção que se estima verdadeira, $q=(1-p)$, n número de observações, $\mathrm{N}=$ universo amostral ${ }^{6}$.

Imagem 1: fórmula

a) Fórmulas $e=z_{a / 2} \sqrt{\frac{p \cdot q}{n}} \cdot \sqrt{\frac{N-n}{N-1}}$

Destes julgados, contabilizou-se o tempo entre a interposição do RESE e o seu julgamento. A partir dos dados colhidos, verificou-se quantos dias eram necessários entre o ajuizamento do recurso e a prolação do acórdão, bem como os dados de tendência central e os dados de dispersão.

Coletaram-se os seguintes indicadores: se a interposição do RESE foi motivada por uma decisão de pronúncia ou por outra decisão qualquer; se o recorrente foi o Ministério Público ou a defesa do acusado; se o resultado foi favorável ao recorrente ou não; as datas de protocolo do recurso e do seu respectivo julgamento, e se a decisão foi proferida por unanimidade ou se houve divergência.

A partir dos dados coletados pelos indicadores, segregou-se a diferença entre as datas de interposição e as de prolação do acórdão, para indicar o tempo de julgamento dos RESE. Ademais, verificou-se a correlação entre os dados e os prazos mencionados. Coletados estes marcadores, utilizou-se o método de regressão linear para averiguar a interferência estatística entre os marcadores. Este modelo serve para indicar se é significativa a alteração de um dado em relação a de outro7.

\subsection{Resultados da análise de dados}

Feito isso, é visível o impacto nos fluxos processuais no procedimento do júri diante de alterações nos mecanismos jurídicos ou extrajurídicos que abarcam esta fase procedimental, apresentando como consequência um notório aumento da interposição de RESE. Deste modo, a alteração nos fluxos das varas do Tribunal do Júri tem consequência na interposição de maior número deste recurso, decorrente do crescimento das decisões de pronúncia.

6 CHAVES NETO, Anselmo; LUCHESA, Cláudio J. - Cálculo do espaço amostral em pesquisas em administração. Curitiba: Edição do autor, 2011. [consultado em 2021-04-14]. Disponível em: https://www.unicuritiba.edu.br/images/calculo_do_tamanho_da_amostra_texto_final_para_impressapso1.pdf.

7 IBM. Regressão linear. 2019. [consultado em 2021-04-14]. Disponível em: <https://www.ibm.com/br-pt/analytics/learn/linear-regression>. 
Nesse sentido, o Programa Tempo de Justiça afigura-se como fator que implicou em maior número de decisões de pronúncia proferidas pelas varas do Tribunal do Júri, o que gerou aumento na quantidade de RESE interpostos nas Câmaras Criminais do TJCE contra estas decisões.

Diante da disposição em rol dos dados globais, obteve-se o fluxo temporal no TJCE, considerando as datas de interposição e de julgamento, a fim de avaliar em quanto tempo ocorreram os julgamentos e o impacto nos acervos processuais. 0 gráfico abaixo mostra uma linha de tendência regressiva, isto é, um afunilamento, no qual os processos mais recentes apresentam tempo de julgamento menor.

Verifica-se que há um incremento na quantidade de julgamentos dos RESE no período estudado, com intensificação dos julgados nos anos de 2016 e 2017. Esta intensificação é menor no ano de 2018, mas ainda assim tem-se mais julgados analisados em comparação aos anos anteriores, conforme se pode observar a seguir.

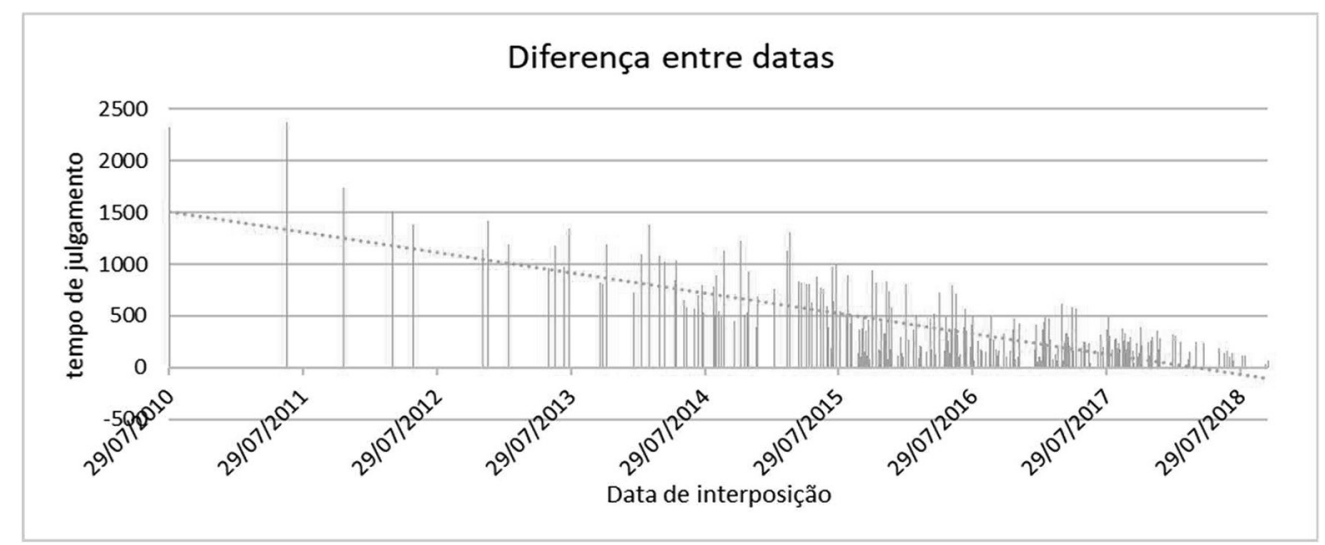

Portanto, a partir da pesquisa quantitativa realizada, constatou-se que o Programa Tempo de Justiça impactou não apenas o primeiro grau de jurisdição, mas também o segundo grau, diante do aumento da quantidade de RESE interpostos e julgados.

\section{Análise qualitativa dos fundamentos dos acórdãos coletados}

Superada a análise quantitativa acerca do tempo necessário ao julgamento dos RESE, será feita a análise qualitativa dos fundamentos jurídicos utilizados nos acórdãos proferidos pelas Câmaras Criminais do TJCE. É preciso averiguar o conteúdo jurídico do princípio "in dubio pro societate", frequentemente utilizado para fundamentar as decisões de pronúncia no rito do Tribunal do Júri, confrontando-o com o princípio "in dubio pro reo", previsto de forma expressa na CF.

Os dois princípios versam sobre a dúvida no processo penal, mas enquanto o "in dubio pro reo" é normalmente aplicado na sentença e favoravelmente ao acusado, o "in dubio pro societate" é aplicado nas decisões interlocutórias, quando do juízo de admissibilidade da acusação, favorável ao jus puniendi estatal, e não ao réu.

\section{Gráfico 1}

Data de interposição $x$ tempo de julgamento.

\section{Fonte}

Coleta de dados. 
Defende-se que, diante da dúvida, é mais aceitável absolver um culpado do que processar e culpar um inocente por um crime que não cometeu. Então, no procedimento do Tribunal do Júri, diante da insuficiência de provas, entende-se que o juiz não deve pronunciar o réu, aplicando, igualmente nessa fase, o princípio "in dubio pro reo". Diante de inflexões como a correlação dúvida e presunção do estado de inocência, considera-se inaplicável o princípio "in dubio pro societate".

O principal reflexo da diferenciação do procedimento do Tribunal do Júri em relação ao procedimento comum consiste no fato do mérito da sentença ser julgado com base no senso comum, visto que a decisão é tomada por indivíduos leigos com diferentes percepções de mundo, representando à sociedade por meio da aplicação direta do poder do povo nos casos de crimes dolosos contra a vida ${ }^{8}$.

A partir da análise das atas das sessões de julgamento, percebe-se que o princípio "in dubio pro societate" é automaticamente utilizado para fundamentar as decisões de pronúncia no procedimento do Tribunal do Júri, em especial após a implantação do Programa Tempo de Justiça, que tem como principal objetivo diminuir o tempo de tramitação dos processos. Defende-se que não é razoável, em nome da mera concretização da celeridade no julgamento dos processos de homicídio com autoria conhecida, que os direitos fundamentais e as garantias processuais do acusado sejam desrespeitados, conduzindo a julgamentos injustos.

O princípio "in dubio pro reo" tem assento tanto no texto constitucional (art. 5०, LVII, da (F), quanto tem amparo infra legal (art. 386, VII, do CPP), ao passo que o "in dubio pro societate", desprovido de qualquer previsão normativa, pode acarretar o desvirtuamento das premissas racionais de valoração da prova, esvaziando a função da decisão de pronúncia.

Por todo o exposto, é de fundamental importância que o procedimento do Tribunal do Júri resguarde as garantias processuais do acusado, com especial aplicação do princípio "in dubio pro reo" também nas decisões de pronúncia, ao invés do "in dubio pro societate", visto que só é correto pronunciar o réu quando houver prova concreta da autoria e materialidade do crime.

\section{Conclusão}

A partir da pesquisa quantitativa realizada, é possível afirmar que a implantação do Programa Tempo de Justiça aumentou a eficiência das varas do Tribunal do Júri, impactando não apenas o primeiro grau de jurisdição, mas também o segundo grau, diante do aumento da quantidade de RESE interpostos e julgados das decisões de pronúncia.

Assim, uma das consequências imediatamente verificadas foi o aumento da quantidade de julgamentos de RESE, o qual coincidiu com o início dos trabalhos da Terceira

8 SANTIAGO, Nestor Eduardo Araruna et al. - Dúvida e processo penal: procedimento do tribunal do júri, decisão de pronúncia e o “in dubio pro societate”. “Católica Law Review”, v.3, n. 3, nov. 2019, pp. 43-61. 
Câmara Criminal do TJCE, que iniciou suas atividades a partir do segundo semestre do ano de 2016. Tal fato justifica a escolha do início do lapso temporal analisado, ou seja, no mês de agosto de 2016, perdurando a análise até dezembro de 2018.

Verificou-se que o prazo entre a interposição e o julgamento dos RESE diminuiu após a realização do Programa Tempo de Justiça, aumentando a celeridade de tramitação dos processos que versam sobre crimes de homicídio com autoria conhecida. Pode-se inferir que a alteração nos fluxos das varas do Tribunal do Júri refletiu no ajuizamento de maior número de RESE no período analisado, demonstrando que o Programa Tempo de Justiça impactou positivamente na celeridade processual e contribuiu para efetivação do princípio da razoável duração do processo no âmbito das varas do Tribunal do Júri.

Sabe-se que, mesmo diante de uma instrução probatória realizada sob o crivo do contraditório e da ampla defesa, fatos controversos e nebulosos podem persistir, ocasionando dúvida ao órgão jurisdicional. Nos referidos casos, defende-se que o mais adequado é o magistrado aplicar o preceito constitucional da presunção de inocência, adotando-se o princípio "in dubio pro reo" quando houver dúvida na prolação da decisão de pronúncia.

Diante do exposto, conclui-se que o "in dubio pro societate" sucumbe ao "in dubio pro reo", quando persiste a dúvida na decisão de pronúncia, considerando que o primeiro não possui nenhum fundamento constitucional ou legal. 